Review began 10/27/2021 Review ended 11/02/2021 Published 11/06/2021

๑) Copyright 2021

Silva et al. This is an open access article distributed under the terms of the Creative Commons Attribution License CC-BY 4.0. which permits unrestricted use, distribution, and reproduction in any medium, provided the original author and source are credited.

\section{Idiopathic Hypereosinophilic Syndrome Presenting With Embolic Stroke}

\author{
Magda S. Silva ${ }^{1}$, Carina Ramalho ${ }^{1}$, Francelino Ferreira ${ }^{1}$, Inês Maia ${ }^{1}$, Anneke Joosten ${ }^{1}$ \\ 1. Internal Medicine Department, Centro Hospitalar Barreiro Montijo, Barreiro, PRT
}

Corresponding author: Magda S. Silva, magdasgsilva@gmail.com

\begin{abstract}
Hypereosinophilic syndrome is a rare condition characterized by eosinophilia associated with organ damage, most commonly affecting the skin, lung, gastrointestinal, cardiovascular and central nervous system. The idiopathic form is characterized by the absence of other conditions associated with hypereosinophilia such as allergies, infectious, hematological, immunological, endocrine or neoplasm diseases. The authors present a clinical case of a 70-year-old man with no relevant history, who went to the emergency department for neurological deficits and nonspecific chest pain. Laboratory tests revealed marked eosinophilia, elevation of cardiac enzymes with normal electrocardiogram. Computed tomography of the head showed multiple bilateral ischemic lesions. Upon further investigation for the cerebrovascular disease, transesophageal echocardiogram showed a thrombus at the aortic arch, as a probable embolic source. Despite anticoagulant therapy and corticosteroids, the patient's status deteriorated, with multiple successive ischemic strokes and worsening neurological deficits. After a thorough investigation, the diagnosis of idiopathic eosinophilia was established.
\end{abstract}

Categories: Cardiology, Internal Medicine, Neurology

Keywords: hypereosinophilic syndrome, stroke, thrombosis, aorta, idiopathic

\section{Introduction}

Hypereosinophilic syndrome (HES) is a rare entity characterized by eosinophilia associated with organ damage, most frequently affecting the skin, lungs, central nervous systems, gastrointestinal and cardiovascular systems. The idiopathic form is defined by the absence of other entities associated with hypereosinophilia. The clinical spectrum is highly variable and depends on the organs infiltrated by eosinophils, which cause inflammation, fibrosis, vasculitis and thrombosis. It is hypothesised that the neurological symptoms result from direct effects caused by eosinophils, but can also be secondary to thromboembolic phenomena, a serious complication of HES as we reported in the clinical case.

\section{Case Presentation}

A 70-year-old man with no relevant past or recent medical history, went to the emergency department due to disorientation, decreased muscle strength in the upper limbs and nonspecific chest pain with three days of evolution. Upon observation, he was apyretic and hemodynamically stable. Cardiopulmonary auscultation and abdominal examination revealed no alterations. In the neurological examination, we highlighted the temporal-spatial disorientation, proximal plegia of the upper limbs, paresis of the lower limbs and extended cutaneous-plantar reflex on the left side. We observed small linear subungual hemorrhages (Figure 1) and a lesion with necrotic background measuring approximately $5 \mathrm{~mm}$ in the distal portion of the right lower limb (Figure 2). 


\section{Cureus}

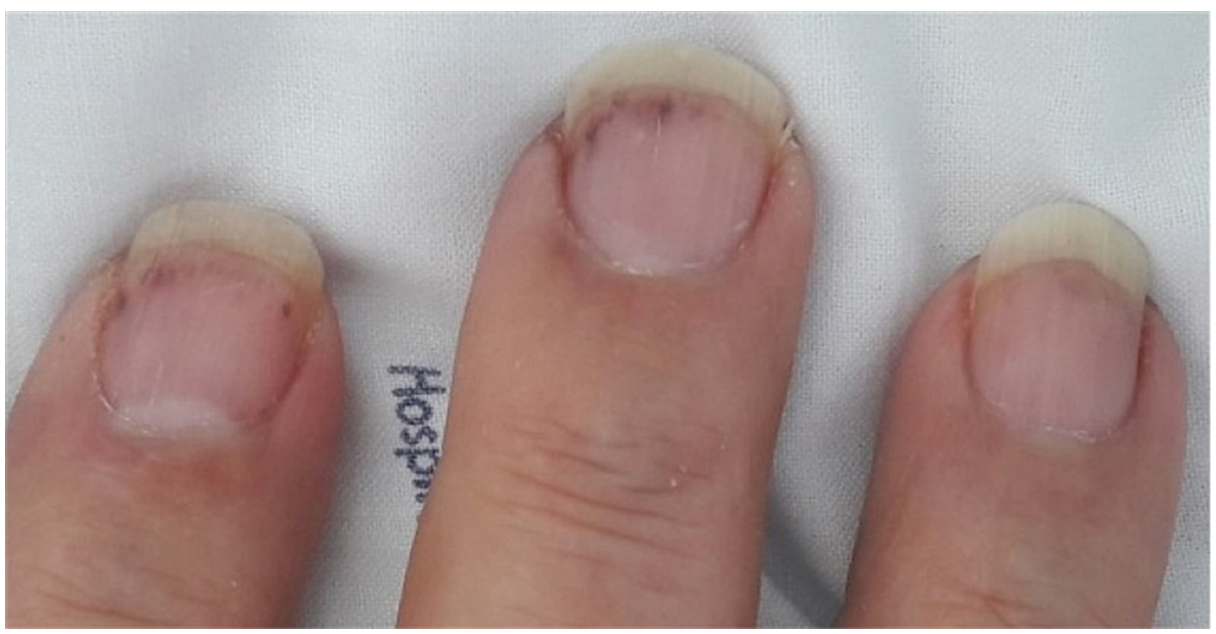

FIGURE 1: Linear subungual hemorrhages (splinter hemorrhage).

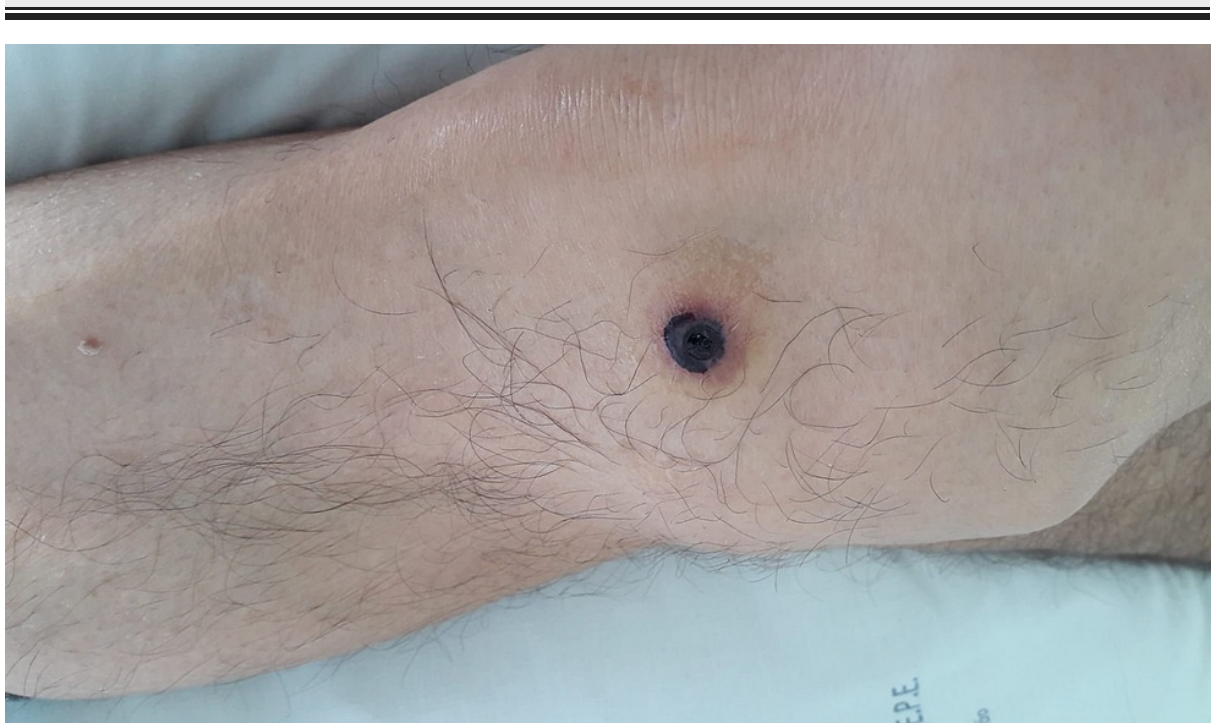

FIGURE 2: A lesion with necrotic background measuring approximately $5 \mathrm{~mm}$ in the right lower limb.

Laboratory evaluation revealed 18,900 leukocytes/uL with eosinophilia of 9853/uL, and troponin elevation $(7.2 \mathrm{ng} / \mathrm{ml})$ with normal electrocardiogram. Cranioencephalic computed tomography (CT scan) showed ischemic lesions in several territories, better defined by brain magnetic resonance which documented multiple bilateral frontoparietal and right occipitotemporal lesions (Figure 3). Transesophageal echocardiography showed a mass measuring $7 \times 14 \mathrm{~mm}$ in the arch of the aorta, compatible with a thrombus (Figure 4), confirmed by magnetic resonance imaging. The echocardiogram also showed left ventricular hypertrophy, with preserved systolic function and no restrictive pattern. Holter and echo-Doppler of carotid and vertebral arteries were normal. 


\section{Cureus}
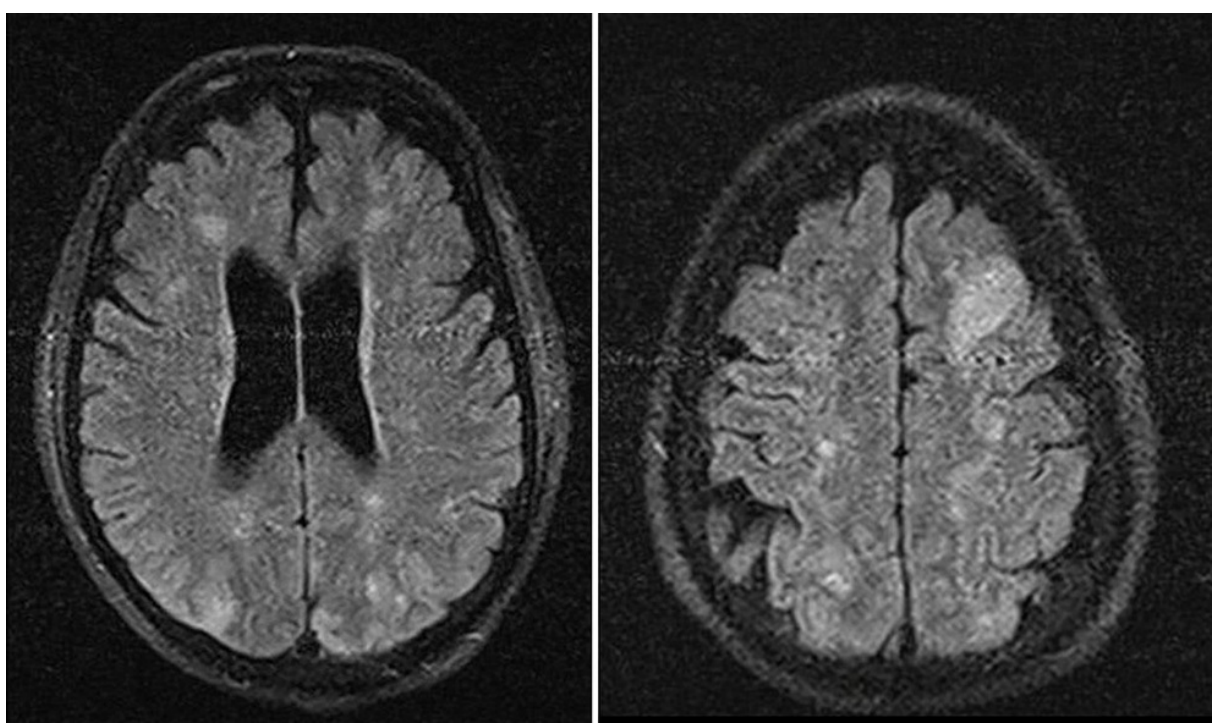

FIGURE 3: Multiple bilateral frontoparietal lesions, predominantly right, observed on brain magnetic resonance.

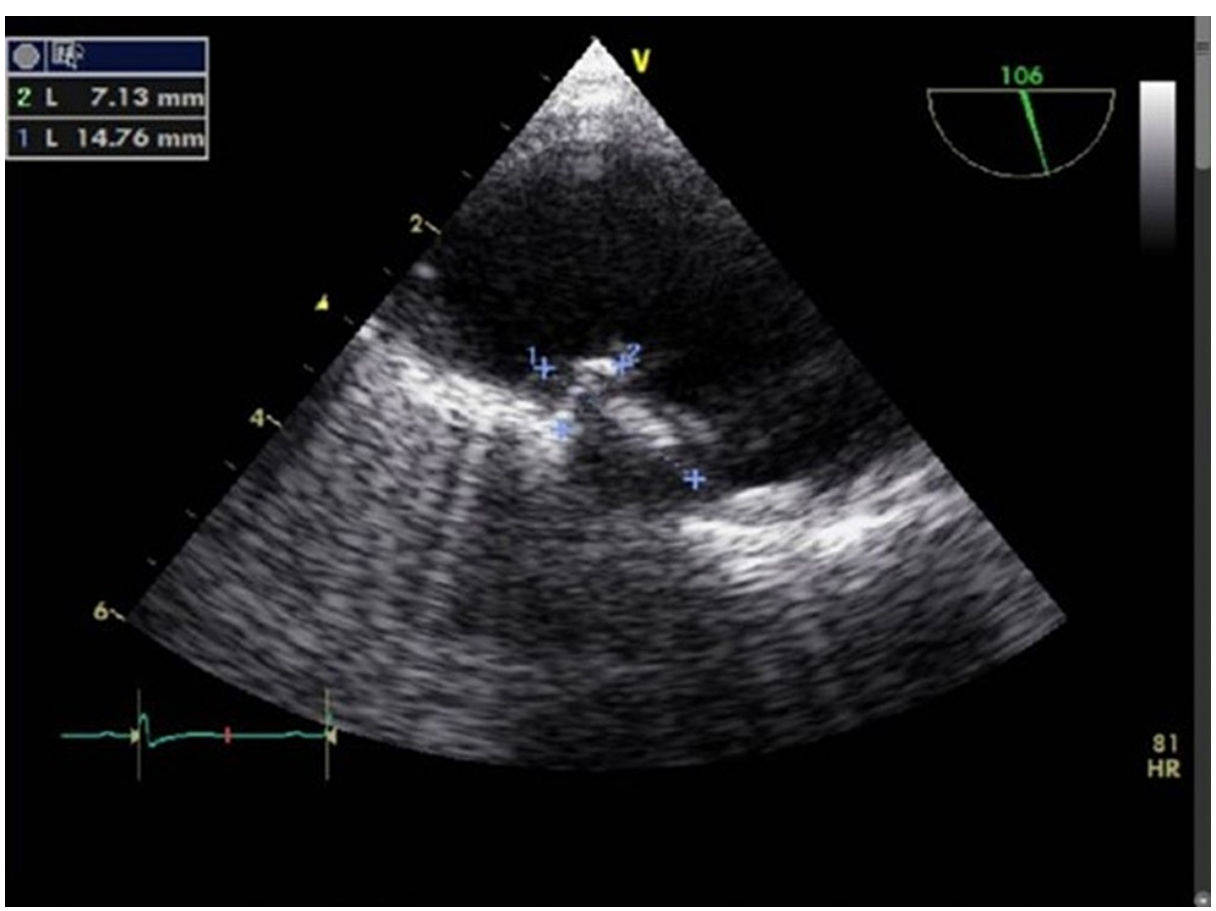

FIGURE 4: Thrombus in the aortic arch seen on transesophageal echocardiography.

In the presence of eosinophilia with organ damage, we started therapy with methylprednisolone $1 \mathrm{~g} /$ day for five days (followed by prednisolone $60 \mathrm{mg} /$ day), anticoagulation with enoxaparin $1 \mathrm{mg} / \mathrm{kg}$ twice daily and antiaggregation with acetylsalicylic acid $100 \mathrm{mg} /$ day. Cardiac enzymes returned to normal levels and a gradual decline in eosinophils (up to 1200/uL after six weeks).

Other exams like abdominal ultrasound and body CT scan did not reveal abnormalities; skeletal radiography showed no calcified or lytic lesions; microbiological and parasitological tests were negative; viral serologies were negative; bone marrow analysis showed $18.6 \%$ eosinophils and no atypical cells; study of genetic mutations associated with clonal forms of eosinophilia was negative; the study of vasculitis and

thrombophilia was negative (Table 1). As the investigation did not result in an etiology for eosinophilia, we admitted that it was an idiopathic form. 


\section{Cureus}

\begin{tabular}{|c|c|c|c|}
\hline Laboratory tests & Admission & Discharge & Reference values \\
\hline Hemoglobin (g/dl) & 13.1 & 11.6 & $13-17$ \\
\hline Leukocytes /uL & 18,900 & 7700 & $4000-11,000$ \\
\hline Neutrophils /uL & 7400 & 4900 & $2100-7500$ \\
\hline Eosinophils /uL & 9853 & 1200 & $0-500$ \\
\hline Lymphocytes /uL & 960 & 1100 & $1000-4000$ \\
\hline Monocytes /uL & 450 & 500 & $100-1000$ \\
\hline Basophils /uL & 220 & 0 & $0-200$ \\
\hline Platelets /uL & 179,000 & 272,000 & $150,000-400,000$ \\
\hline International Normalized Ratio & 1.1 & & $0.8-1.2$ \\
\hline D-dimers (ug/L) & 1811 & & $<500$ \\
\hline Creatinine (mg/dl) & 1.15 & & $0.7-1.3$ \\
\hline Urea (mg/dl) & 53 & & $<50$ \\
\hline Sodium (mEq/L) & 140 & & 135-147 \\
\hline Potassium (mEq/L) & 4.3 & & $3.7-5.1$ \\
\hline Troponin T (ng/ml) & 7.2 & 0.02 & $<0.03$ \\
\hline Creatinine kinases (U/L) & 281 & & 32-294 \\
\hline Creatinine kinases - myocardial band (ng/ml) & 48 & & $<5$ \\
\hline Natriuretic peptide (pg/ml) & 928 & & $<100$ \\
\hline Aspartate aminotransferase (U/L) & 29 & & $<34$ \\
\hline Alanine aminotransferase (U/L) & 25 & & $<35$ \\
\hline gamma-glutamyl transpeptidase (U/L) & 20 & & $12-64$ \\
\hline Reactive C protein (mg/dl) & 10.5 & & $<0.5$ \\
\hline Thyroid Stimulating Hormone (mU/L) & 1.87 & & $0.4-4.5$ \\
\hline Free T4 (ng/dl) & 1.4 & & $0.7-1.8$ \\
\hline Vitamin B12 (pg/ml) & 430 & & $300-900$ \\
\hline Protein C, protein S and antithrombin III & \multicolumn{3}{|l|}{ Normal } \\
\hline 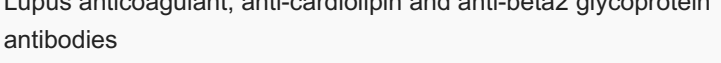 & \multicolumn{3}{|l|}{ Normal } \\
\hline ANA, ANCA & \multicolumn{3}{|l|}{ Negative } \\
\hline Peripheral blood smear & \multicolumn{3}{|c|}{ eosinophilia, without atypical cells } \\
\hline Myelogram & \multicolumn{3}{|c|}{$\begin{array}{l}18.6 \% \text { eosinophils ( } 16.6 \% \text { mature), no myelodysplasia or atypical } \\
\text { cells }\end{array}$} \\
\hline Genetic study & \multicolumn{3}{|c|}{ No mutations: PDGFRa, PDGFRb, BCR-ABL, CBFB, JAK2 } \\
\hline Protein Electrophoresis & \multicolumn{3}{|c|}{ No monoclonal pattern } \\
\hline Total IgE (Ul/ml) & 433 & & $<100$ \\
\hline HIV, Hepatitis B and C & \multicolumn{3}{|l|}{ Negative } \\
\hline Antibodies for Treponema pallidum & \multicolumn{3}{|l|}{ Negative } \\
\hline Antibodies for CMV, EBV and herpes simplex & \multicolumn{3}{|l|}{ Negative } \\
\hline Antibodies for Leptospira and Borrelia & \multicolumn{3}{|l|}{ Negative } \\
\hline
\end{tabular}




\section{Cureus}

$\begin{array}{|lll|}\text { Feces } & \text { Microbiological exam } & \text { Negative } \\ & \text { Parasitological exam } & \text { No protozoan cysts or Helminth eggs were observed } \\ \text { Blood cultures } & \text { Negative } \\ \text { Urine culture } & \text { Negative }\end{array}$

\section{TABLE 1: Laboratory tests}

ANA - antinuclear antibodies; ANCA - antineutrophil cytoplasmic antibodies; BCR-ABL - breakpoint cluster region-abelson gene; CBFB - core-binding factor beta; CMV - cytomegalovirus; EBV - Epstein-Barr virus; HIV - human immunodeficiency virus; IgE - Immunoglobulin E; JAK2 - Janus kinase 2; PDGFRa - platelet-derived growth factor receptor, alpha polypeptide; PDGFRb - platelet-derived growth factor receptor, beta polypeptide.

Despite corticosteroids therapy, anticoagulation and antiaggregation, the patient deteriorated with generalized hypertonia, new focal deficits - left central facial paresis, dysphagia and dysarthria, with evidence of new lesions on brain CT scan.

\section{Discussion}

HES has an estimated prevalence between 0.36 to 6.3 per 100,000 and is more common in men in the proportion of 9:1 [1,2]. It is defined by persistent eosinophilia (peripheral blood eosinophil count greater than $1500 / \mathrm{uL}$ in at least two determinations [3,4]) and organ damage. It can be classified as: primary (clonal) relating to myeloid/lymphoid hematologic neoplasms and leukemias, with the proliferation of eosinophils and associating with mutations PDGFRa, PDGFRb, FGFR1, JAK2 or CBFB [5]; secondary (or reactive) that relates with allergic diseases, drug hypersensitivity reactions, infections, lymphomas, some solid tumors, connective tissue diseases, sarcoidosis, ulcerative colitis and vasculitis $[5,6]$; idiopathic - diagnosis of exclusion that corresponds to about $80 \%$ of cases [7]. Clinical presentation, as well as prognosis, is highly variable and depends on the underlying etiology and on the affected organs (most often the skin, heart, lungs, gastrointestinal tract and central nervous system [8]).

Eosinophils are granulocytic cells that contain active substances that directly exert their toxic effect, as well as cytokines that promote the activation of other cells and the inflammatory cascade. In the presence of hypereosinophilia, there is an unregulated release of these substances that cause damage by phenomena of inflammation, fibrosis, vasculitis and thrombosis [5].

Cardiovascular complications occur in 40 to $60 \%$ of cases [9] and are the major cause of morbidity and mortality [10]. A classic presentation of eosinophilic infiltration is Loeffler's endocarditis, in which there is thickening and fibrosis of the endocardium and consequent restrictive cardiomyopathy [11]. Cardiac involvement usually occurs in three phases: necrotic (acute, in which there is myocardial infiltration by eosinophils), thrombotic and fibrotic [10]. The clinical presentation can vary from heart failure, angor, arrhythmias, pericarditis and thrombotic phenomena (as we observed in this clinical case). Cardiac involvement can lead to the appearance of characteristic skin lesions named linear subungual hemorrhages (splinter hemorrhages), nail bed infarctions and ulcers, which usually occur in the necrotic phase [9,10]. Lab tests may show an increase in cardiac enzymes, d-dimers and type B natriuretic peptide. The electrocardiogram may be normal or show alterations in ventricular repolarization. The echocardiogram may reveal thrombi and alterations in cardiac function with a restrictive pattern $[12,13]$. Definitive diagnosis can be made by biopsy, but cardiac magnetic resonance is sensitive and non-invasive [10,14].

Neurological involvement is another important complication with an estimated incidence of stroke of $12 \%$ [15]. There are several mechanisms involved, the most important being embolization from a cardiac source [9]. Clinical presentation includes transient ischemic attacks and multifocal ischemic strokes (with additive deficits and high recurrence rates, even under anticoagulation and antiaggregation [9-12]), behavioral changes and confusional states (in the presence of encephalopathy caused by eosinophilic infiltration) and, more rarely, seizures and peripheral neuropathy [9].

The finding of potentially fatal HES complications is an indication for early treatment. Corticosteroids are one of the pillars of therapy [5]. Other therapeutic options, especially for patients refractory to corticosteroids, include hydroxyurea, interferon alpha and anti-interleukin 5 . In the presence of cardiac thrombi, anticoagulation is indicated.

In this patient, despite the reduction in the number of eosinophils with therapy, there was a clinical worsening conditioned by thromboembolic phenomena, typically associated with a worse prognosis.

\section{Conclusions}

This clinical case illustrates the complexity of this disease and its diagnostic process in an attempt to 
identify its etiology. The wide spectrum of presentations makes the diagnosis of HES a challenging one, and it must be remembered whenever eosinophilia and organ damage present in a patient. This pathology involves multidisciplinarity, with the internist being the patient's manager and articulating with other specialties such as Immunology, Infectiology, Cardiology and Neurology.

\section{Additional Information \\ Disclosures}

Human subjects: Consent was obtained or waived by all participants in this study. Conflicts of interest: In compliance with the ICMJE uniform disclosure form, all authors declare the following: Payment/services info: All authors have declared that no financial support was received from any organization for the submitted work. Financial relationships: All authors have declared that they have no financial relationships at present or within the previous three years with any organizations that might have an interest in the submitted work. Other relationships: All authors have declared that there are no other relationships or activities that could appear to have influenced the submitted work.

\section{References}

1. Crane MM, Chang CM, Kobayashi MG, Weller PF: Incidence of myeloproliferative hypereosinophilic syndrome in the United States and an estimate of all hypereosinophilic syndrome incidence. J Allergy Clin Immunol. 2010, 126:179-181. 10.1016/j.jaci.2010.03.035

2. Duarte AM, Krause LF, Carpes A, Backes DS, Santos BZ: Síndrome hipereosinofilica: revisão de literatura . Disciplinarum Scientia. 2012, 13:265-274.

3. Dispenza MC, Bochner BS: Diagnosis and novel approaches to the treatment of hypereosinophilic syndromes. Curr Hematol Malig Rep. 2018, 13:191-201. 10.1007/s11899-018-0448-8

4. Wilkins HJ, Crane MM, Copeland K, Williams WV: Hypereosinophilic syndrome: an update. Am J Hematol. 2005, 80:148-157. 10.1002/ajh.20423

5. Klion AD: How I treat hypereosinophilic syndromes. Blood. 2015, 126:1069-1077. 10.1182/blood-2014-11551614

6. Klion A: Hypereosinophilic syndrome: current approach to diagnosis and treatment. Annu Rev Med. 2009, 60:293-306. 10.1146/annurev.med.60.062107.090340

7. Ogbogu PU, Bochner BS, Butterfield JH, et al.: Hypereosinophilic syndrome: a multicenter, retrospective analysis of clinical characteristics and response to therapy. J Allergy Clin Immunol. 2009, 124:1319-1325. 10.1016/j.jaci.2009.09.022

8. Roufosse F, Weller PF: Practical approach to the patient with hypereosinophilia. J Allergy Clin Immunol. 2010, 126:39-44. 10.1016/j.jaci.2010.04.011

9. Curtis C, Ogbogu P: Hypereosinophilic syndrome. Clin Rev Allergy Immunol. 2016, 50:240-251. 10.1007/s12016-015-8506-7

10. Ogbogu PU, Rosing DR, Horne MK 3rd: Cardiovascular manifestations of hypereosinophilic syndromes . Immunol Allergy Clin North Am. 2007, 27:457-475. 10.1016/j.iac.2007.07.001

11. Gao M, Zhang W, Zhao W, Qin L, Pei F, Zheng Y: Loeffler endocarditis as a rare cause of heart failure with preserved ejection fraction: a case report and review of literature. Medicine (Baltimore). 2018, 97 :e0079. 10.1097/MD.0000000000010079

12. Khwaja GA, Duggal A, Kulkarni A, et al.: Hypereosinophilia-an unusual cause of multiple embolic strokes and multi-organ dysfunction. J Clin Diagn Res. 2013, 7:2316-2318. 10.7860/JCDR/2013/6004.3512

13. Mankad R, Bonnichsen C, Mankad S: Hypereosinophilic syndrome: cardiac diagnosis and management. Heart. 2016, 102:100-106. 10.1136/heartjnl-2015-307959

14. Syed IS, Martinez MW, Feng DL, Glockner JF: Cardiac magnetic resonance imaging of eosinophilic endomyocardial disease. Int J Cardiol. 2008, 126:e50-e52. 10.1016/j.ijcard.2007.01.019

15. Sethi HS, Schmidley JW: Cerebral infarcts in the setting of eosinophilia: three cases and a discussion . Arch Neurol. 2010, 67:1275-1277. 10.1001/archneurol.2010.256 